\title{
EXPERIMENTAL STUDY OF MICROWAVE SLOW WAVE COMB APPLICATORS FOR TIMBER TREATMENT AT FREQUENCIES 2.45 AND 0.922GHz
}

\section{GRAHAM BRODIE ${ }^{1}$, YURIY PCHELNIKOV ${ }^{2}$ and GRIGORY TORGOVNIKOV ${ }^{3}$}

${ }^{1}$ The University of Melbourne

Faculty of Veterinary and Agricultural Sciences

Dookie Campus

940 Nalinga Rd.

Dookie, Victoria, 3647

Australia

e-mail: grahamb@unimelb.edu.au

${ }^{2}$ Company: PchelnikovCosulting.Slow-Wave Structures Application 104 Drexelbrook Ct

Cary, NC 27519

USA

e-mail: yupchel@gmail.com

${ }^{3}$ The University of Melbourne

School of Ecosystem and Forest Sciences

4 Water St., Creswick

Victoria 3363

Australia

e-mail: grigori@unimelb.edu.au

Keywords and phrases: comb applicator, microwave, microwave wood treatment, slow wave applicator, timber.

Received January 23, 2018; Revised February 13, 2018

(C) 2018 Scientific Advances Publishers 


\begin{abstract}
Slow wave comb applicators for timber (and other materials) treatment at frequencies $2.45 \mathrm{GHz}$ (Comb1) and $0.922 \mathrm{GHz}$ (Comb2), designed for surface layer heating, modification and sterilization, were experimentally studied. Experiments showed that the Comb1 applicator released $83-88 \%$ of applied MW energy in wet wood on the depth up to $30 \mathrm{~mm}$, in zones with maximum energy application. In other zones, energy application efficiency is higher. The Comb2 applicator releases about $60 \%$ of the applied energy on the depth up to $30 \mathrm{~mm}$ in the zones of maximum energy release. Energy distribution from the comb applicators, in the wet wood, allows the most significant part of the energy to be released in surface layers and increases efficiency of energy use, compared to other MW radiators. Comb1 and Comb2 are recommended for practical use in wood heating, MW modification and sterilization processes. They can be used for soil, concrete, plaster, bricks, plastics and other materials were required heating of surface layers.
\end{abstract}

\title{
1. Introduction
}

Microwave (MW) processing technologies are developing rapidly in all industries. This arises from: the high efficiency of converting electricity into microwave energy, energy savings associated with rapid in-depth heating of materials, specific interactions that can be achieved between microwaves and materials, radical acceleration of technological processes, reductions in MW equipment costs and improvements in the reliability of industrial MW equipment. In the timber industry, MW wood processing is used for wood heating, drying [1, 2], bending [4], and modification for increasing wood permeability for liquids and gases [12] to allow better impregnation with preservatives $[8,10,13,16]$, resins, plastics, and alloys [11].

A number of wood species have a very low permeability causing problems during timber processing. These processing problems include, very long drying times, large material losses after drying, expensive drying processes and difficult impregnation with preservatives and resins. In the wood pulping industry low wood permeability results in shallow chemical penetration of pulping liquids into wood. This requires the use of small sized chips, high chemical usage and high energy 
consumption. MW wood modification can provide an increase in wood permeability, that solves many wood processing problems [14]. Intensive MW power applied to green wood generates steam pressure within the wood cells. Under high internal pressure, the pit membranes in cell walls, tyloses in vessels and weak ray cells are ruptured to form pathways for easy transportation of liquids and vapours [15]. A several thousand-fold increase in wood permeability in the radial and longitudinal directions can be achieved in species previously found to be impermeable to liquids and gases.

For timber modification, it is required to supply to wood with very high intensity MW power and maximum possible uniformity, which traditional MW devices (chambers, resonators, antennas) cannot provide. In many cases in industry it is required to heat or treat only the surface layers of different material (timber, soil, concrete and so on) using MW. For example, for soil sterilisation (weed killing) it is required to treat soil only to a depth of $25 \mathrm{~mm}$ [3]. Traditional MW irradiators (antennas) cannot provide only surface heating and energy penetrates deep into the material, where the energy decays exponentially due to absorption into the material. Energy losses, if the application requires heating only to a depth 20-60mm (for example, to modify only wood surface layers by MW for preservative treatment or impregnation with resins), is very significant. Therefore, special MW radiators are required for surface treatment to increase process efficiency.

To achieve good surface heating efficiency the slow wave (which are often called "surface waves") comb (SWC) structure was studied. The main property of slow waves is the energy concentration near the impedance electrode, - i.e., the comb surface. Previously, slow wave structures (SWS) were used mostly as delay lines [17] and as interaction circuits in MW vacuum devices, and their properties were explored for these specific applications [7]. Adapting MW technologies to industry, medicine, and military applications initiated a study of slow wave 
structure properties and peculiarities which can be used for developing novel technologies [5, 18]. It was shown by the full-wave analysis as well as by experiments and practical realization [19] that the SWSs have many previously unknown peculiarities, which can be used for creating novel technologies for industrial heating.

Usually in wood technology, MW radiators (for example, horns or slot radiators) form heating zones with high nonuniformity, which leads to overheating in some surface zones. Also, energy penetration into the material is too deep, which leads to significant energy losses. Comb applicators can provide effective MW energy release in the wood surface layers by keeping energy close to the comb surface and limiting energy penetration into the material. This leads to significant energy savings.

The research and development objectives were to: design and manufacture slow wave comb structures - irradiators (applicators) for wood treatment at frequencies of $2.45 \mathrm{GHz}$ and $0.922 \mathrm{GHz}$; study the opportunities to use these slow wave comb structures for surface wood layers heating; experimentally study the energy distribution from the slow wave comb applicators in wood; and develop recommendation for practical use of the slow wave comb applicators.

\section{Design of Slow Wave Comb Applicators}

The operational limits of slow-wave applicators depend on the geometry of the comb, especially the comb's depth. When the comb's depth approaches zero, the comb appears like a short circuit and behaves

like the wall of a wave guide. When the comb's depth approaches $\frac{\pi}{k^{\prime}}$, where $k^{\prime}$ is the wave number of the electromagnetic field, the impedance of the comb approaches infinity and wave propagation is prevented. Within these limits, as the comb's depth increases the electromagnetic wave's propagation speed slows and the heating depth decreases. 
On the base of the theoretical study and modelling of slow wave structures described in [6], the slow wave comb (SWC) applicators for frequency $2.45 \mathrm{GHz}(\mathrm{Comb} 1)$ and $0.922 \mathrm{GHz}(\mathrm{Comb2})$ were designed for treatment of wet materials including wood. Comb applicators, which are shown in Figure 1, were fabricated from aluminium. The main dimensions of the Comb1 and Comb2 applicators are displayed in Table 1.

Table 1. Applicator parameters

\begin{tabular}{|c|c|c|}
\hline Parameters & Comb1 (2.45GHz), mm & Comb2 (0.922GHz), mm \\
\hline Working length & 356 & 346 \\
\hline Applicator thickness & 23 & 37 \\
\hline Applicator width & 150 & 264 \\
\hline Comb electrode width & 100 & 150 \\
\hline Comb electrode thickness & 16 & 120 \\
\hline Comb electrode conic length & 90 & 13 \\
\hline Grove depth & 6 & 8 \\
\hline Grove width & 3 & 8 \\
\hline Comb tooth thickness & 3 & $\begin{array}{c}\text { Alumina }(99 \%) \text { ceramic } \\
\text { plate size } 4 \times 86.5 \times 182 \mathrm{~mm} \\
\text { (4pieces }),(\mathrm{DC}=9.8, \text { loss } \\
\text { tangent } 0.0002)\end{array}$ \\
\hline Ceramic plates & $\begin{array}{c}\text { Alumina }(99 \%) \text { ceramic } \\
(4 \text { pieces }),(\mathrm{DC}=9.8, \text { loss } \\
\text { tangent } 0.0002)\end{array}$ & \begin{tabular}{c} 
size $3 \times 84 \times 146 \mathrm{~mm}$ \\
\hline
\end{tabular} \\
\hline
\end{tabular}


In the experiments, the surface of Comb1 was covered by $3 \mathrm{~mm}$ thick alumina plates (Figure 1), while Comb2 was covered by $4 \mathrm{~mm}$ thick alumina plates (Figure 2).

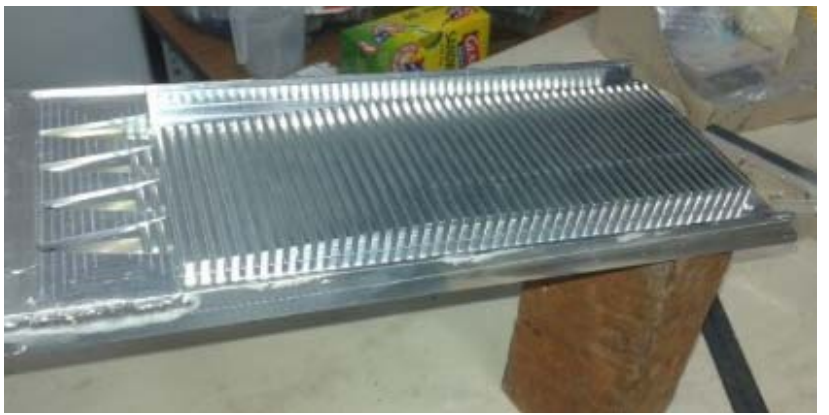

(a)

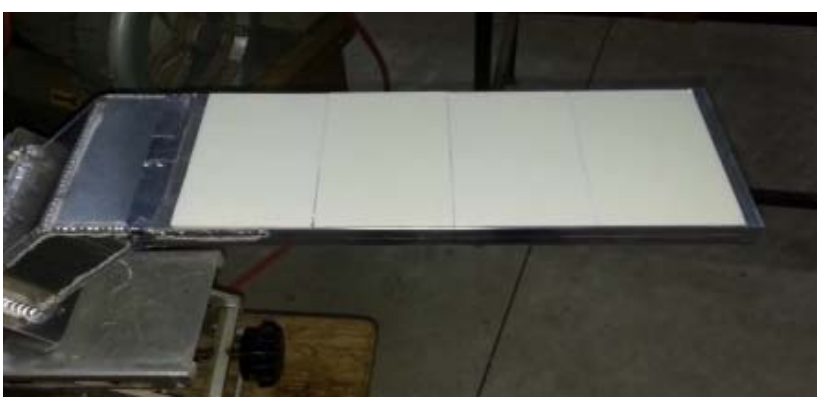

(b)

Figure 1. Comb1 applicator $(2.45 \mathrm{GHz})$ without ceramic plates (a) and with ceramic plates $(3 \times 84 \times 146 \mathrm{~mm}-4 \mathrm{pc})(\mathrm{b})$. 


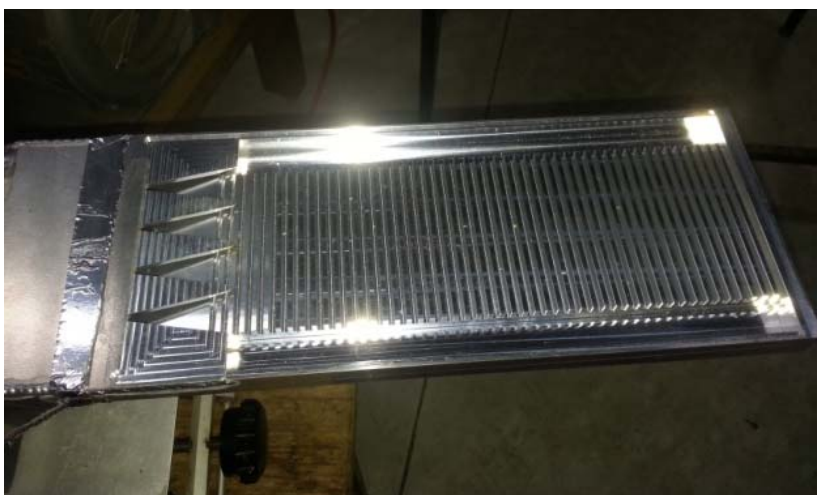

(a)

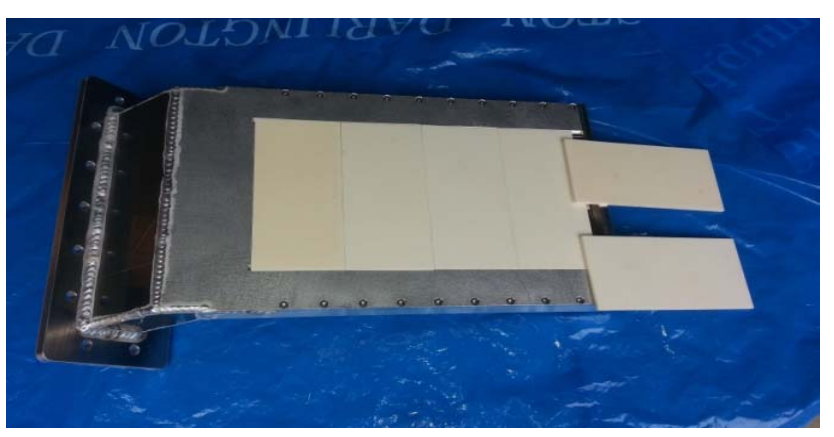

(b)

Figure 2. Comb2 applicator $(0.922 \mathrm{GHz})$ without ceramic plates (a) and with ceramic plates $(4 \times 86.5 \times 182 \mathrm{~mm}-4 \mathrm{pc})(\mathrm{b})$.

\section{Experimental Study: Material and Methods}

\subsection{Material}

Green Radiata pine (Pinus radiata) sawn timber $50 \times 310 \times 450 \mathrm{~mm}$ $\left(\mathrm{MC}=148 \%\right.$, green density $\left.1130 \mathrm{~kg} / \mathrm{m}^{3}\right)$ was used for these tests. Five boards, of $50 \mathrm{~mm}$ thickness, were connected together to form a sample block of $250 \mathrm{~mm}$ thickness (Figure 3). Holes, with a diameter of $2 \mathrm{~mm}$ for temperature measurements by thermocouples, were drilled at distances of $5,15,30,45,95,115,135,165$, and $195 \mathrm{~mm}$ from the beginning of the ceramic plate surfaces of the applicator. The distribution of the holes 
covered the whole volume of the samples along and across the samples. The distances between the rows of holes along the samples were $30 \mathrm{~mm}$ and across the sample was $37.5 \mathrm{~mm}$.

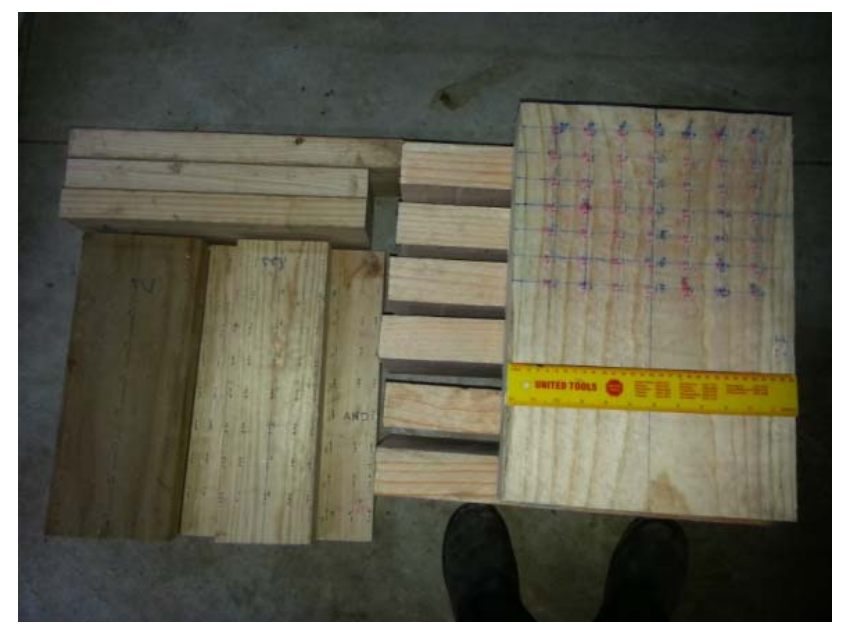

(a)

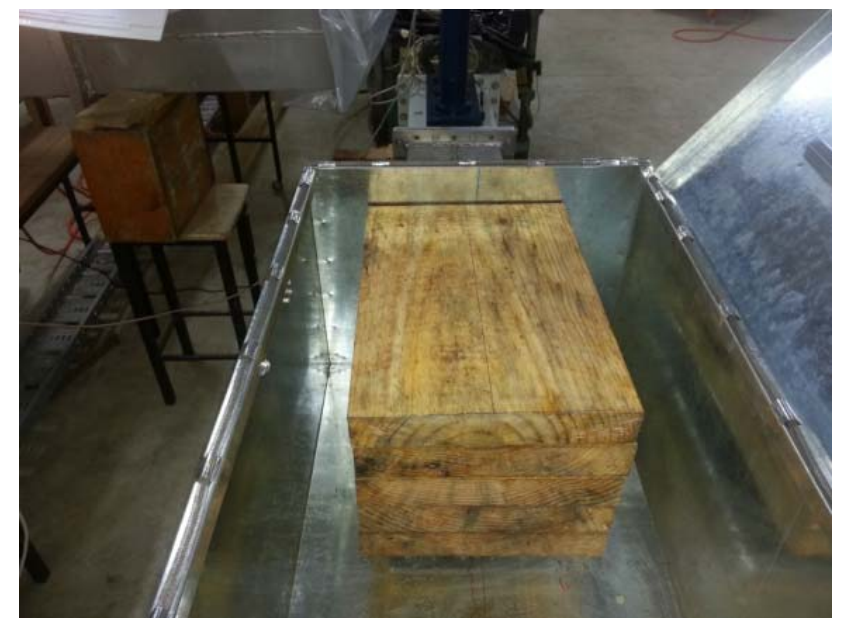

(b)

Figure 3. Samples for tests (a) and $250 \times 310 \times 450 \mathrm{~mm}$ sawn timber block on Comb applicator in leakage protection box. 
Dielectric parameters (dielectric constant and loss tangent) of Radiata pine wood, used for experiments, are presented in Table 2. They depend on frequency, temperature and electric field strength vector $\mathrm{E}$ orientation relative to the wood fibres [9]. In experiments the electric field strength vector $\mathrm{E}$ was orientated perpendicular to the fibres.

Table 2. Dielectric parameters of Radiata pine wood $(\mathrm{MC}=148 \%$, green density $1130 \mathrm{~kg} / \mathrm{m}^{3}$, electric field strength vector $\mathrm{E}$ orientation is perpendicular to fibres)

\begin{tabular}{|c|c|c|c|c|}
\hline \multirow{2}{*}{ Tempe rature, ${ }^{\circ} \mathrm{C}$} & \multicolumn{2}{|c|}{$\mathrm{F}=2.45 \mathrm{GHz}$} & \multicolumn{2}{c|}{$\mathrm{F}=0.922 \mathrm{GHz}$} \\
\hline & Dielectric constant & Loss tangent & Dielectric constant & Loss tangent \\
\hline 20 & 20.5 & 0.15 & 19.8 & 0.14 \\
\hline 50 & 20.5 & 0.14 & 19.8 & 0.13 \\
\hline 90 & 20.5 & 0.12 & 19.8 & 0.12 \\
\hline
\end{tabular}

A scheme of the timber, placed on the applicator, is shown in Figure 4.

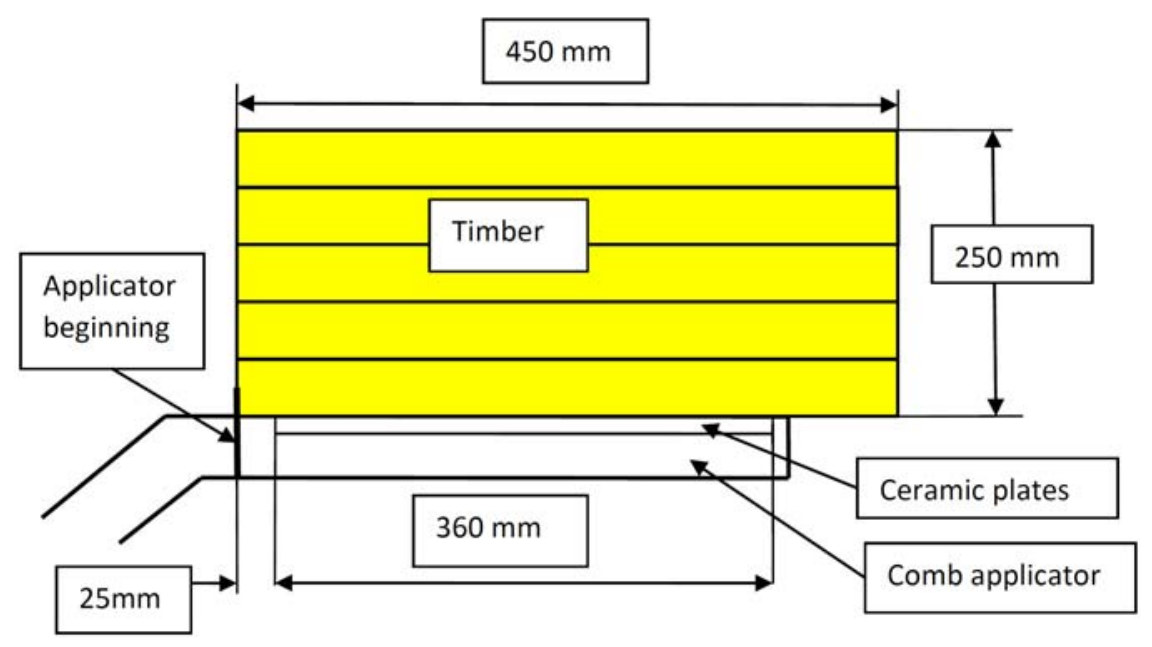

Figure 4. Scheme of comb applicator with wood. 


\subsection{Experimental installations and procedure}

The Comb1 applicator (Figure 1) was connected to a $2.45 \mathrm{GHz} 30 \mathrm{~kW}$ MW generator (Figure 5) and placed to a metal box $(400 \times 500 \times 1120 \mathrm{~mm})$ for leakage protection.

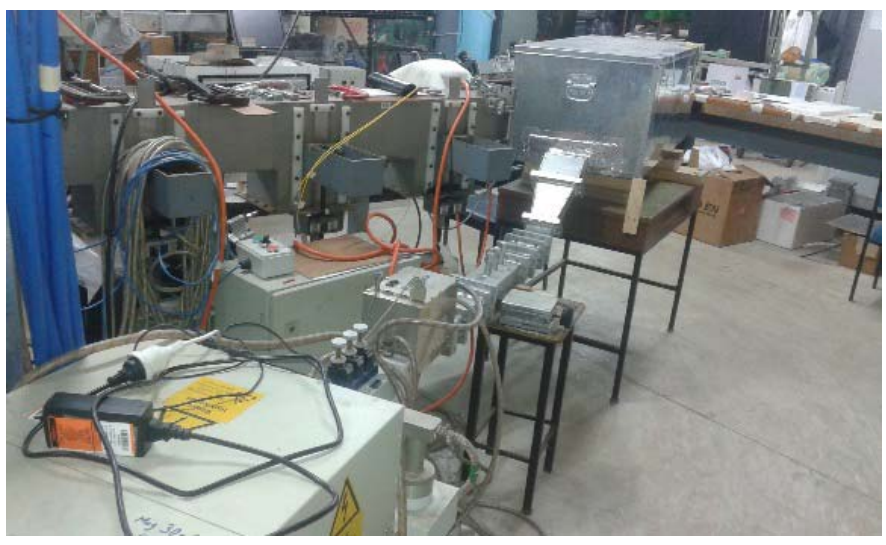

Figure 5. Comb1 applicator (inside of metal box) connection with $30 \mathrm{~kW}$ MW generator $2.45 \mathrm{GHz}$.

The Comb2 applicator was connected to a $0.922 \mathrm{GHz} 60 \mathrm{~kW}$ MW generator (Figure 6) and placed into a metal box for leakage protection. 


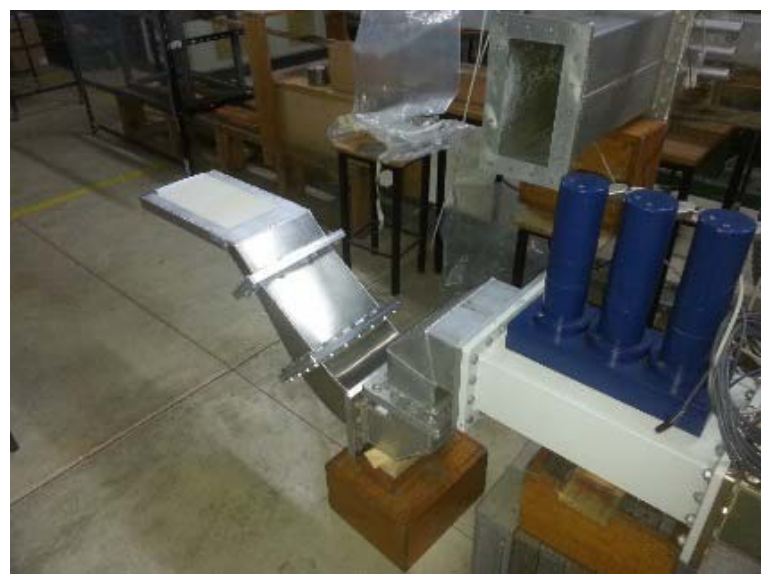

(a)

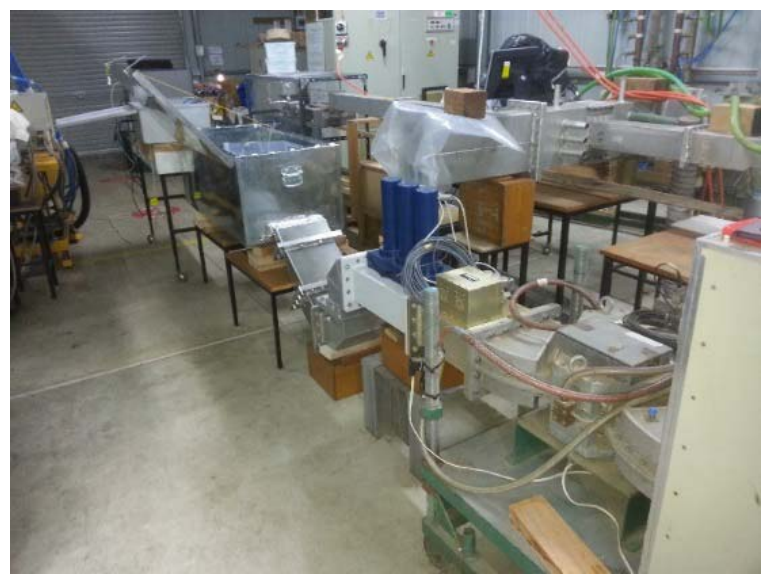

(b)

Figure 6. Comb2 applicator (inside of metal box, (a)) connection with MW generator $60 \mathrm{~kW}, 0.922 \mathrm{GHz}$.

Auto tuners were used in MW systems to provide good matching of the generators and the applicators (with wood). There was practically no power reflection as a result.

Values of MW power and time of the treatment were determined during preliminary tests to provide wood heating at a depth of $10 \mathrm{~mm}$ with no more than $80^{\circ} \mathrm{C}$, to prevent water in the wood from boiling. After 
the timber was placement on the applicator and leakage protection box was closed, MW energy was supplied to the applicators according following schedules:

(1) Applicator Comb1 (2.45GHz)

$\begin{array}{ll}\text { MW applied power } & 3.7 \mathrm{~kW} \\ \text { Time } & 15 \mathrm{sec} \\ \text { Energy } & 56 \mathrm{~kJ} \\ 2) \text { Applicator Comb2 }(0.922 \mathrm{GHz}) & \\ \text { MW applied power } & 9 \mathrm{~kW} \\ \text { Energy } & 180 \mathrm{~kJ} \\ \text { Time } & 20 \mathrm{sec}\end{array}$

After MW heating, temperatures in the wood were measured in the holes using thermocouples. Errors in experiments have the following nature: variability of wood structure and properties, accuracy of temperature measurements, accuracy of MW power measurements, accuracy of time measurements, and accuracy of distances measurements. Preliminary tests showed that temperature variation during 4-5 repetitions at similar conditions was mainly $+/-2^{\circ} \mathrm{C}$. This is acceptable for Comb1 and Comb2 applicator assessment and comparison.

\section{Results of Experiments and Discussion}

\subsection{Temperature distribution in wood by Comb1 applicator (2.45GHz)}

We assume that the temperature distribution in the wood reflects energy release in wood volume and allows us to assess energy distribution from the MW applicators. Figure 7 shows typical temperature distribution in the wood volume, at a depth of $5 \mathrm{~mm}$, after applying MW power of $3.7 \mathrm{~kW}$ for $15 \mathrm{sec}$. 


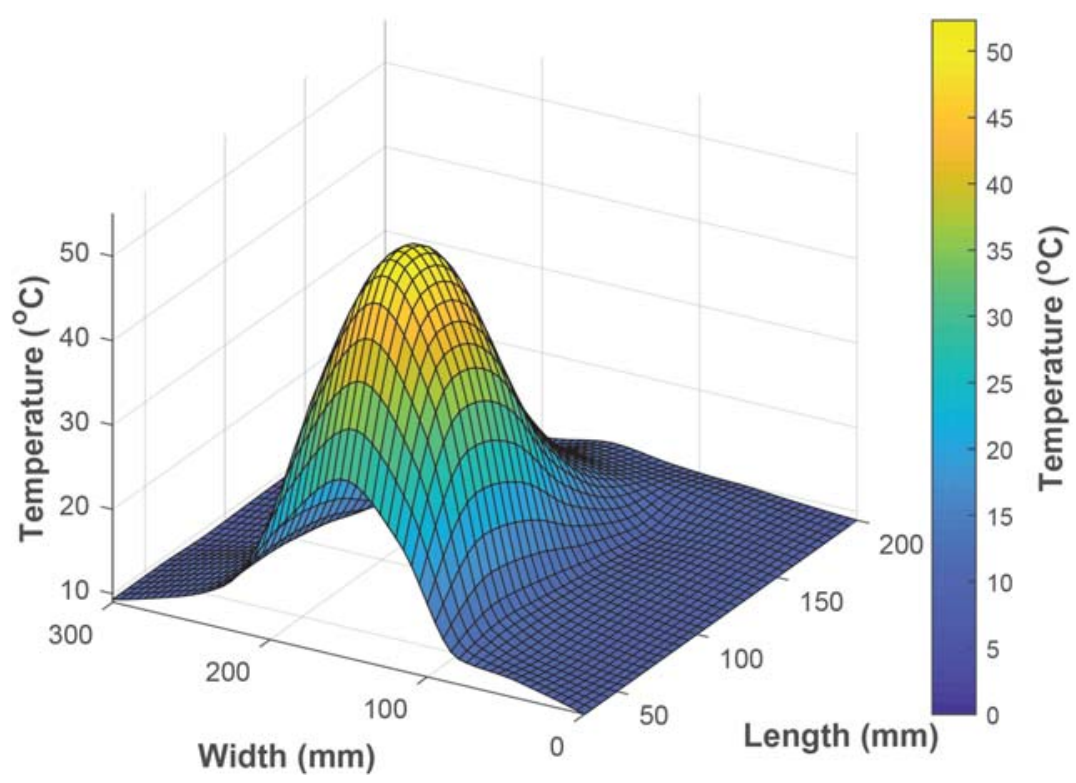

Figure 7. Temperature distribution in wood on the depth $5 \mathrm{~mm}$ by Comb1 applicator at $\mathrm{F}=2.45 \mathrm{GHz}, \mathrm{P}=3.7 \mathrm{~kW}$, time of MW heating $15 \mathrm{sec}, \mathrm{To}=9^{\circ} \mathrm{C}$, applied energy 56kJ. Wood moisture content $148 \%$, green density $1130 \mathrm{~kg} / \mathrm{m}^{3}$.

Temperature distribution after MW heating in timber, at initial temperature $\mathrm{To}=12^{\circ} \mathrm{C}$, along the central vertical plane of the Comb1 applicator, is shown in Figure 8. 


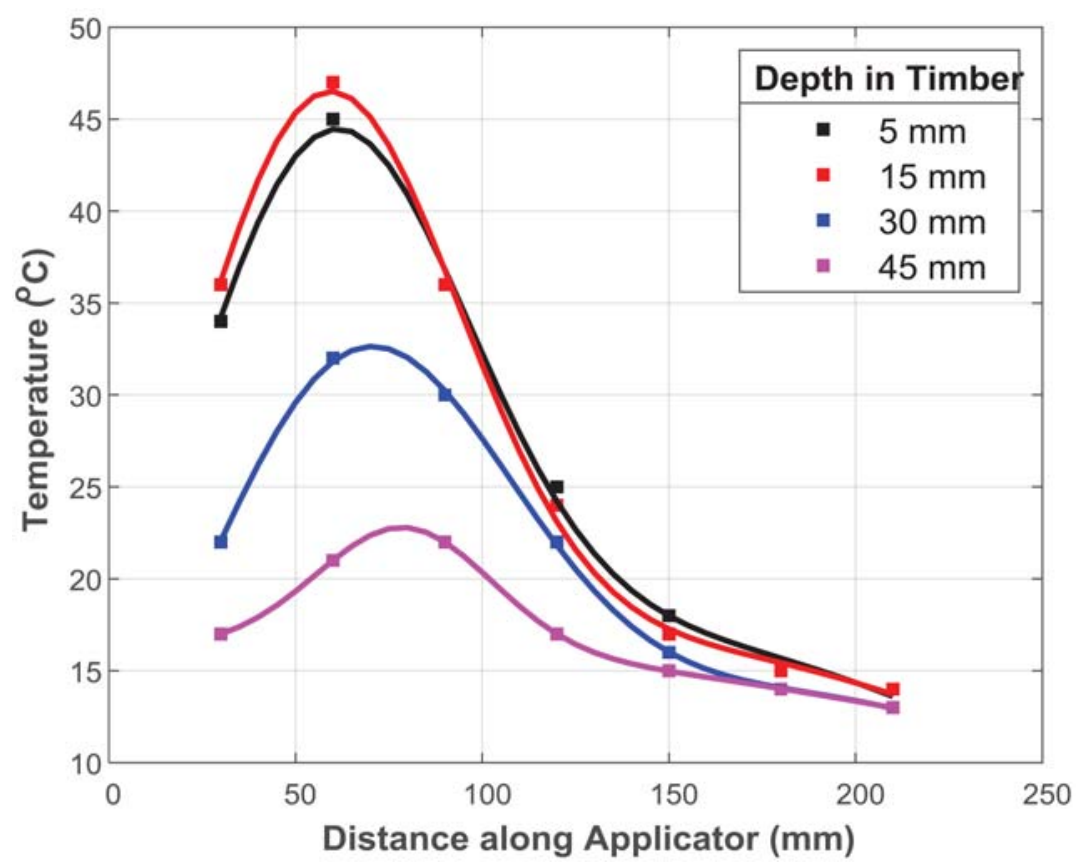

Figure 8. Temperature distribution in the wood sample along the applicator central vertical plane. Sample 12 Radiata pine: $\mathrm{MC}=148 \%$, density $1130 \mathrm{~kg} / \mathrm{m}^{3} . \mathrm{F}=2.45 \mathrm{GHz}, \mathrm{P}=3.7 \mathrm{~kW}$, time of MW heating -15 sec, $\mathrm{To}=12^{\circ} \mathrm{C}$. Applied energy 56kJ.

The maximum energy release take place at about $60 \mathrm{~mm}$ from the beginning of the applicator. Almost all the applied MW energy was absorbed after about $140 \mathrm{~mm}$ from applicator's beginning.

Temperature distribution in the wood sample, across the Comb1 applicator, is displayed in Figure 9. 


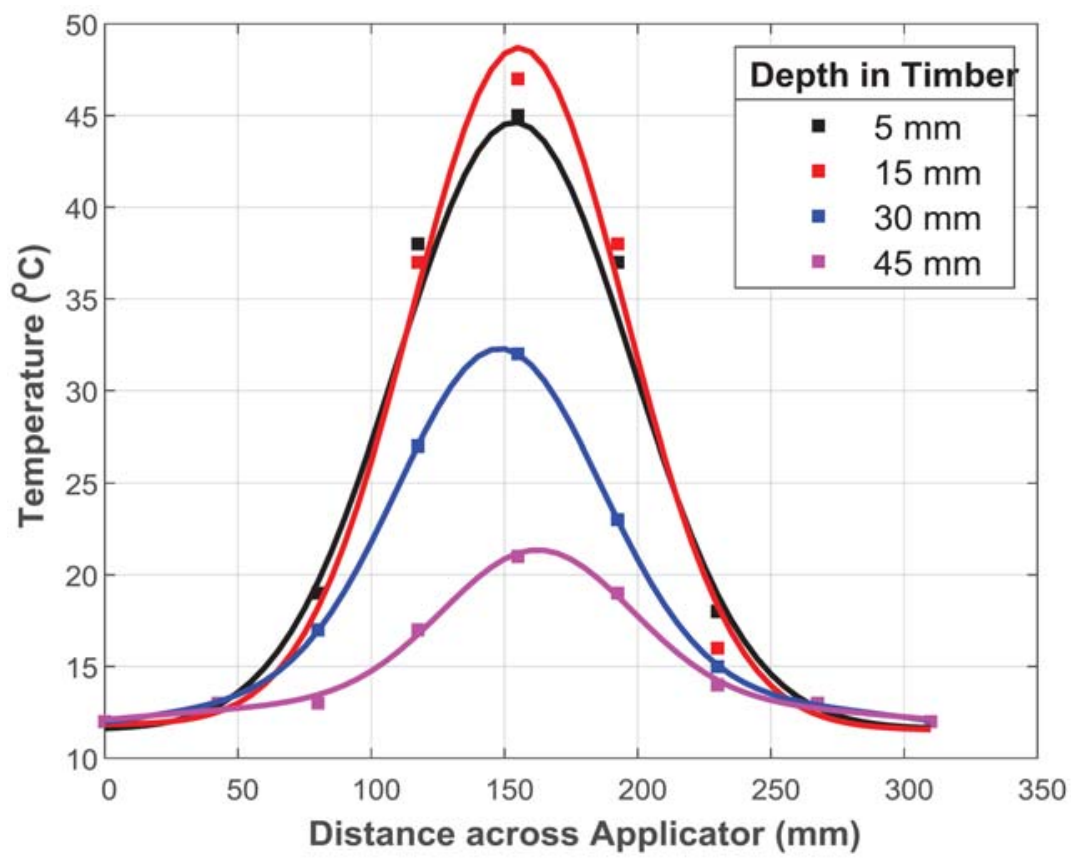

Figure 9. Temperature distribution across the wood sample at the distance $60 \mathrm{~mm}$ from applicator beginning. Sample 12 Radiata pine: $\mathrm{MC}=148 \%$, density $1130 \mathrm{~kg} / \mathrm{m}^{3} . \mathrm{F}=2.45 \mathrm{GHz}, \mathrm{P}=3.7 \mathrm{~kW}$, time of $\mathrm{MW}$ heating $-15 \mathrm{sec}, \mathrm{To}=12^{\circ} \mathrm{C}$. Applied energy 56kJ.

Almost all applied MW energy is absorbed in a width of about $140 \mathrm{~mm}$.

The temperature distribution as a function of depth in central vertical plane of the wood sample is displayed in Figure 10. 


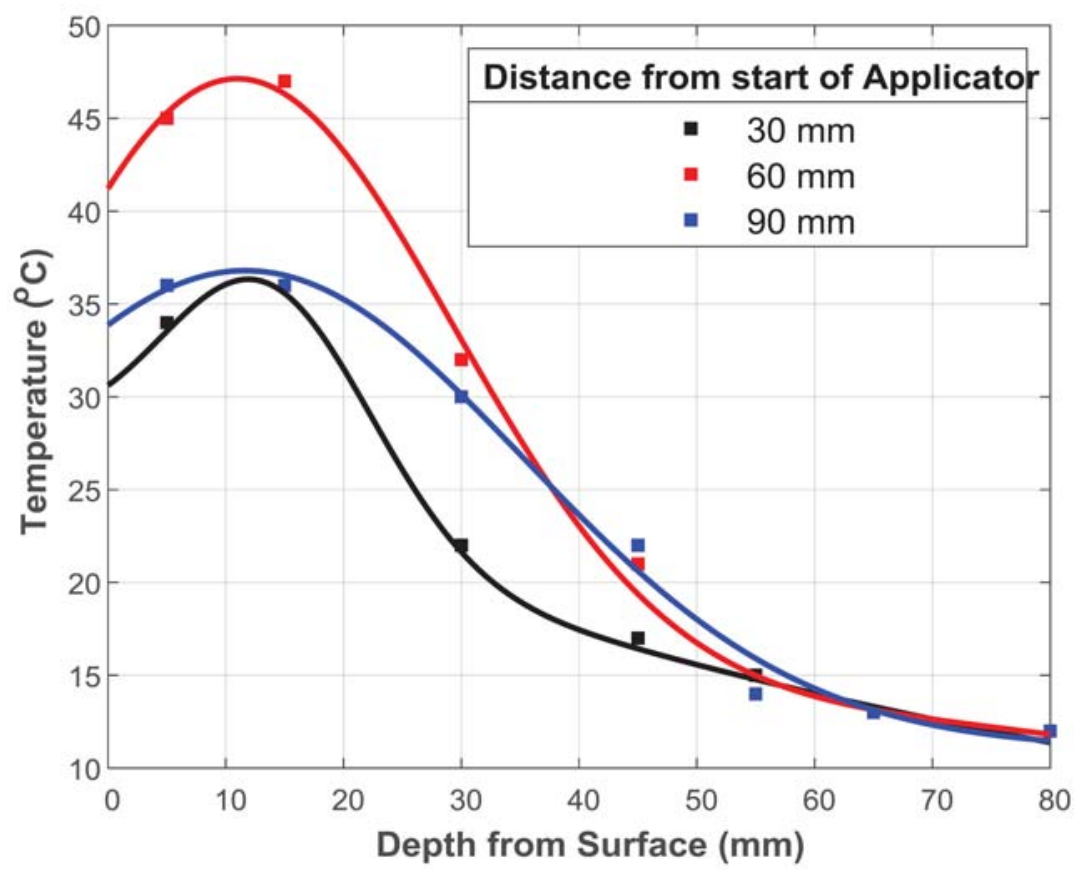

Figure 10. Temperature in depth of the sample in applicator central plane. Wood $\mathrm{MC}=148 \% ; \mathrm{F}=2.45 \mathrm{GHz}, \mathrm{P}=3.7 \mathrm{~kW}$, time of MW heating $-15 \mathrm{sec}$, To $=12^{\circ} \mathrm{C}$. Applied energy $56 \mathrm{~kJ}$.

The most significant part of energy in the zone of maximum power release (30-90mm from applicator beginning) was absorbed on the depth up to $50 \mathrm{~mm}$. In other zones the depth of heating is much lower.

Temperatures at a depth of $5 \mathrm{~mm}$ (curves in Figures 8-10), after MW treatment, are lower compared to temperaure at a of depth $15 \mathrm{~mm}$. This is explained by the influence of more intensive cooling of surface layers during MW processing and during temperature measurement.

Percentage of MW energy absorption, as a function of timber depth (in zone of maximum power release) in the central vertical applicator plane, is shown in Figure 11. 


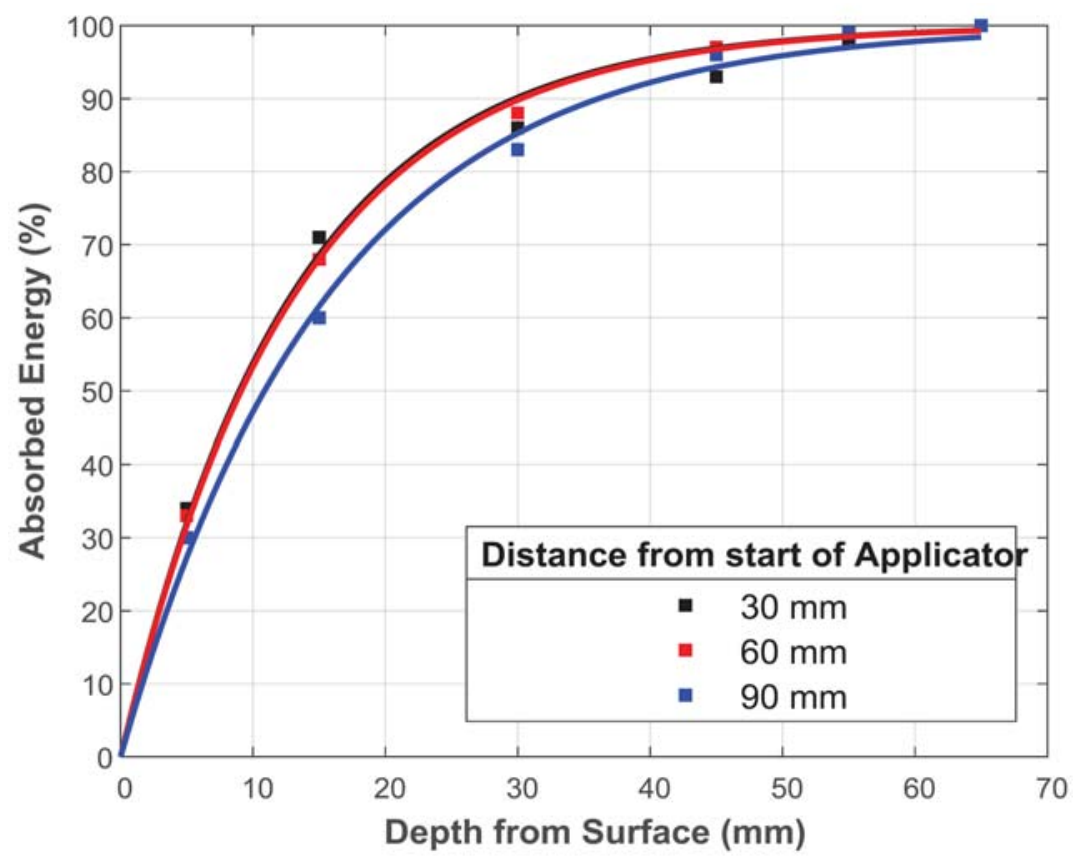

Figure 11. Percentage of MW energy absorption on timber depth in the central vertical Comb1 applicator plane in zone of maximum power release $(2.45 \mathrm{GHz})$.

In the wood sample, with $\mathrm{MC}=148 \%$, the main part of the MW energy was absorbed within about $140 \mathrm{~mm}$ from applicator beginning. Across the sample, almost all the MW energy was absorbed in the central zone width of about $140 \mathrm{~mm}(+/-70 \mathrm{~mm}$ from central plane of the applicator). The average MW specific power, applied by the Comb1 applicator, to wood surface was: $3700(\mathrm{~W}): 14(\mathrm{~cm}) \times 14(\mathrm{~cm})=18.9 \mathrm{~W} / \mathrm{cm}^{2}$ and the average MW energy absorbed was $0.29 \mathrm{~kJ} / \mathrm{cm}^{2}$.

In the central Comb1 applicator zone $(30-90 \mathrm{~mm}$ from applicator beginning), at a depth up to $30 \mathrm{~mm}, 83-88 \%$ of the applied MW energy was absorbed, in all other zones the absorbed percentage of MW energy was higher. 


\subsection{Temperature distribution in wood by Comb2 applicator $(0.922 \mathrm{GHz})$}

Figure 12 shows the typical temperature distribution in wood volume at a depth of $5 \mathrm{~mm}$ after applying $9 \mathrm{~kW}$ of MW power for $20 \mathrm{sec}$ using the Comb2 applicator.

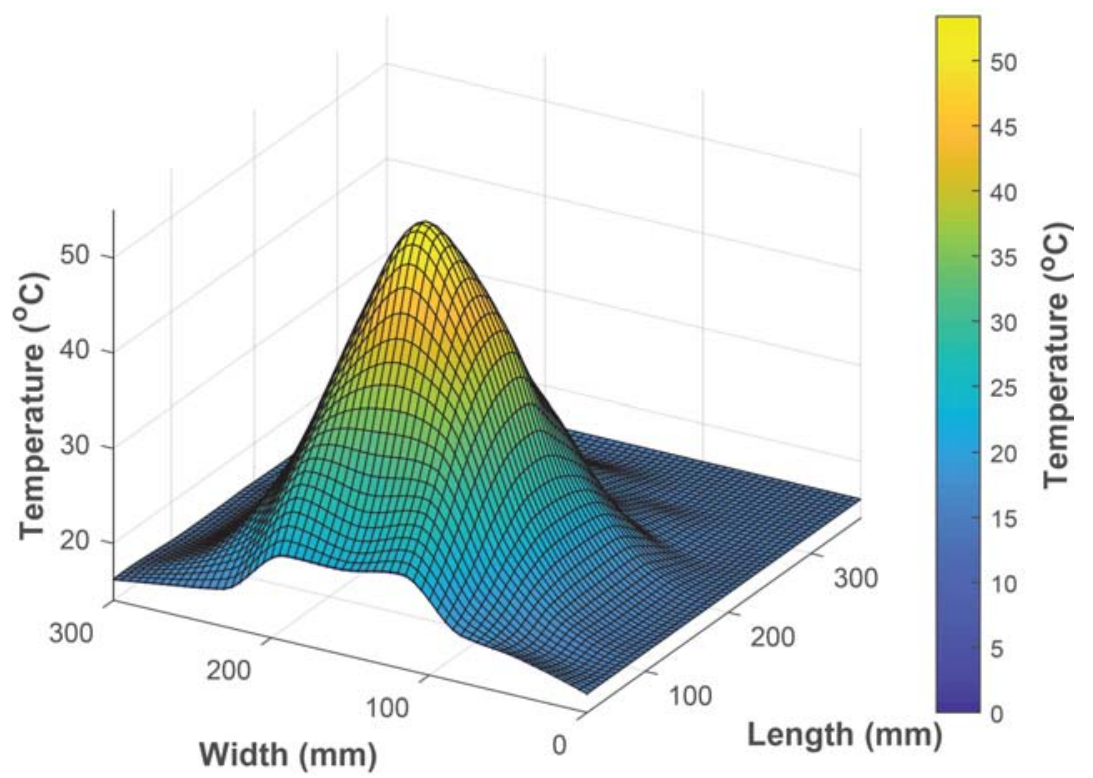

Figure 12. Temperature distribution in the wood sample at $5 \mathrm{~mm}$ depth from the Comb2 applicator at $\mathrm{F}=0.922 \mathrm{GHz}, \mathrm{P}=9 \mathrm{~kW}$, time of $\mathrm{MW}$ heating $20 \mathrm{sec}, \mathrm{To}=12^{\circ} \mathrm{C}$, applied energy $180 \mathrm{~kJ}$. Wood moisture content $\mathrm{MC}=148 \%$, density $1130 \mathrm{~kg} / \mathrm{m}^{3}$.

Temperature measurement results of wood MW heating, using Comb2 at initial timber temperature $15^{\circ} \mathrm{C}-16^{\circ} \mathrm{C}$ and applied energy 180kJ, are displayed in Figures 13, 14, 15.

Experiments showed that practically all the MW energy was absorbed within about 300mm from applicator's beginning (Figure 13). 


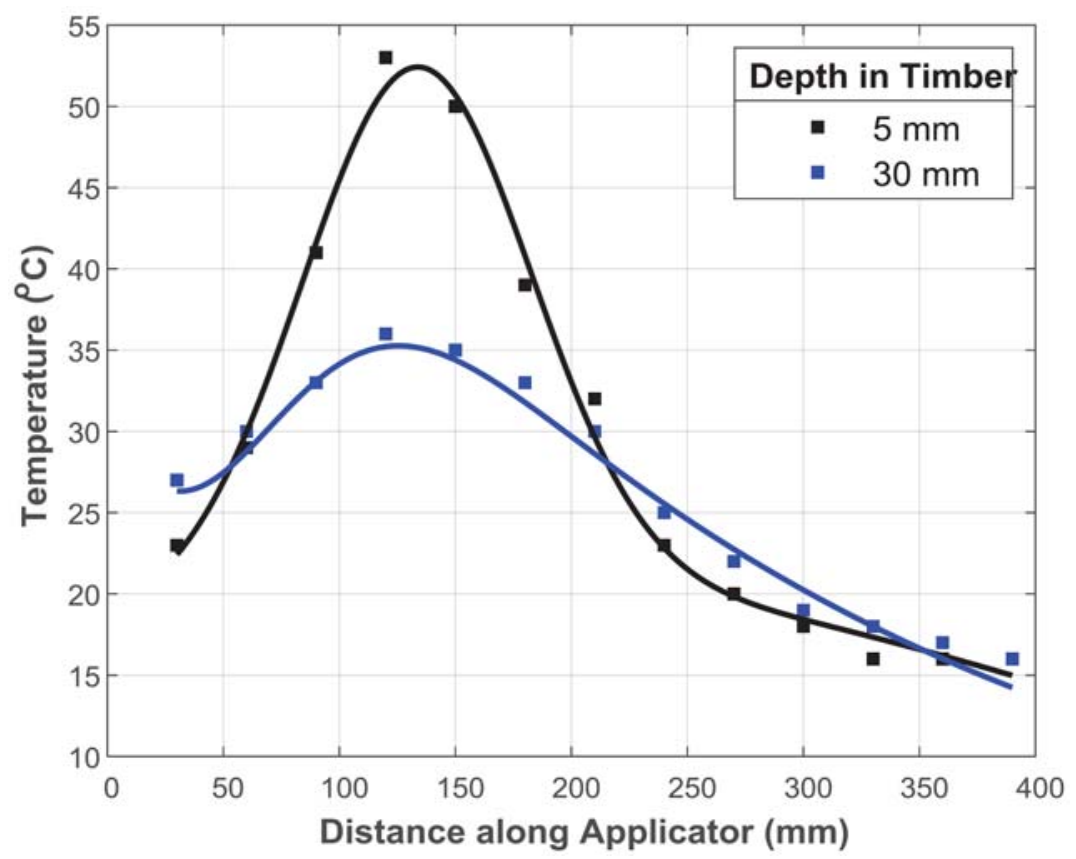

Figure 13. Temperature distribution in the sample along the applicator central vertical plane. Wood thickness $250 \mathrm{~mm}$ (dimensions $250 \times 310 \times 450 \mathrm{~mm}$ ) $\mathrm{MC}=148 \% ; \mathrm{F}=0.922 \mathrm{GHz}, \mathrm{P}=9 \mathrm{~kW}$, time of $\mathrm{MW}$ heating $-20 \mathrm{sec}, \mathrm{To}=16^{\circ} \mathrm{C}$. Applied energy 180kJ.

Most of the energy was absorbed within $260 \mathrm{~mm}$ of applicator beginning, with the maximum energy release taking place at a distance of $120 \mathrm{~mm}$ from applicator's beginning.

Temperature distribution across the sample after MW heating is shown in Figures 14 and 15. 


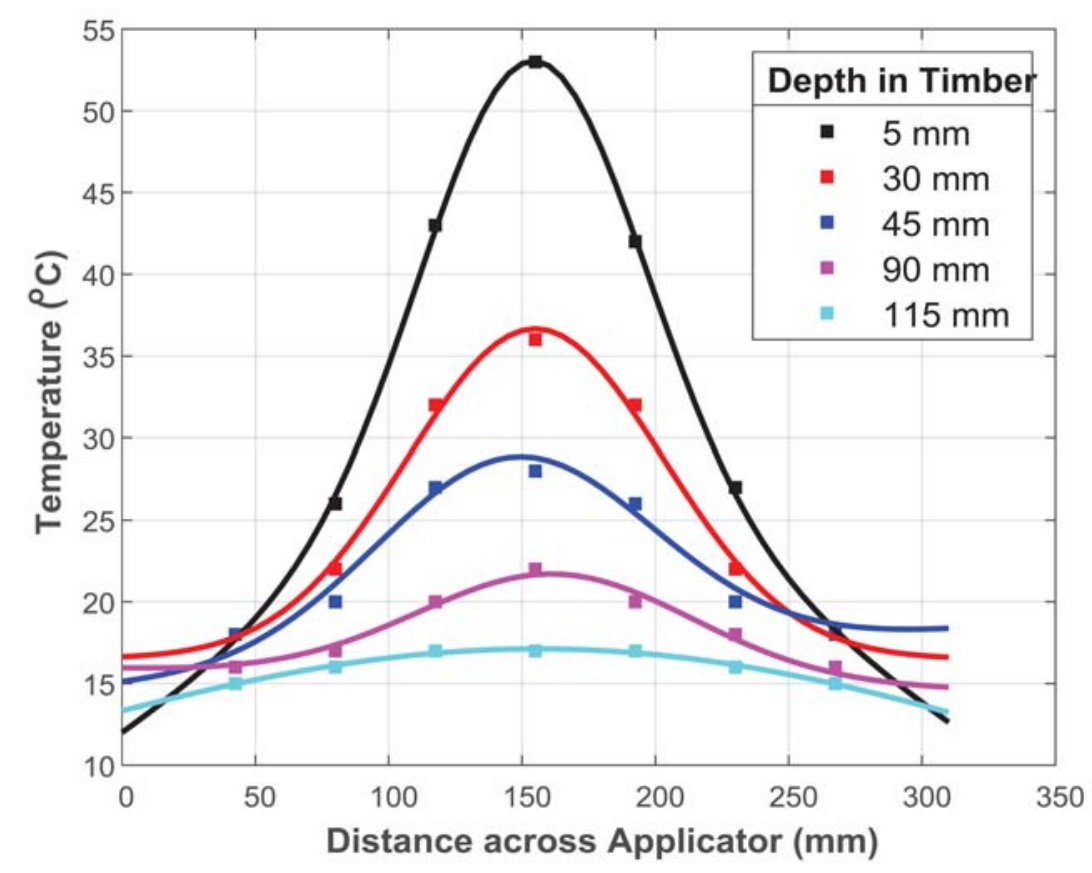

Figure 14. Temperature distribution across the sample at the distance $120 \mathrm{~mm}$ from applicator beginning. Sample of Radiata pine: thickness $250 \mathrm{~mm}(250 \times 310 \times \mathrm{s} 450), \mathrm{MC}=148 \% ; \mathrm{F}=0.922 \mathrm{GHz}, \mathrm{P}=9 \mathrm{~kW}$, time of MW heating $-20 \mathrm{sec}, \mathrm{To}=16^{\circ} \mathrm{C}$. Applied energy 180kJ. 


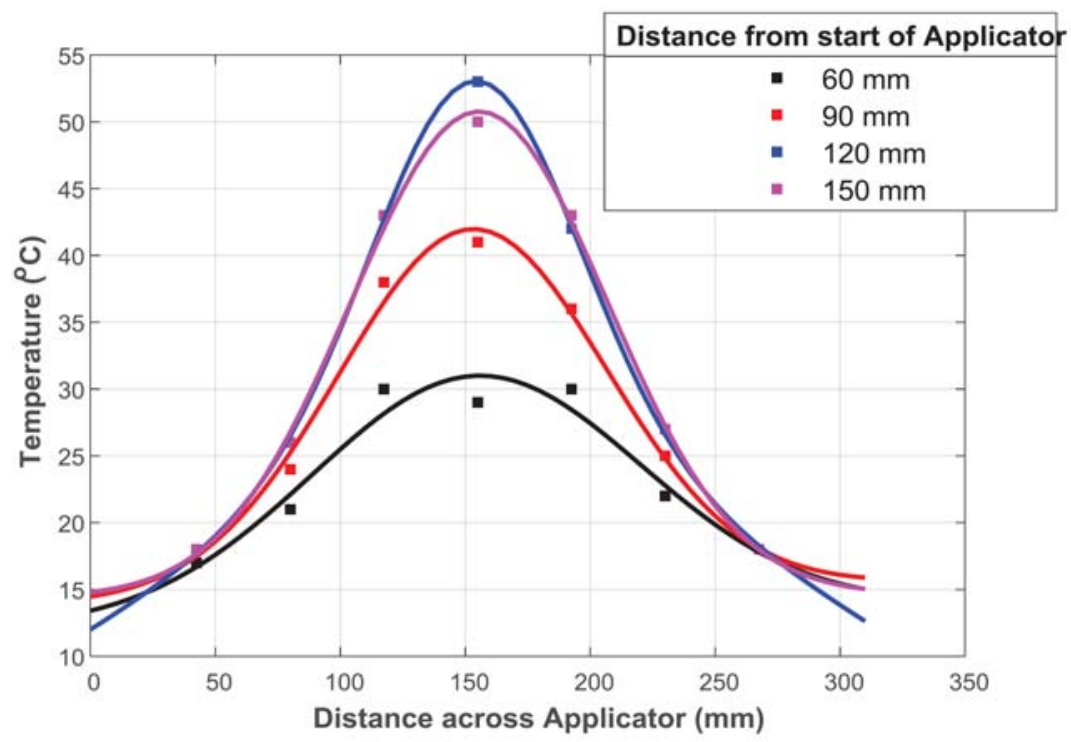

Figure 15. Temperature distribution across the sample at different distances from applicator beginning on the depth $5 \mathrm{~mm}$. Sample of Radiata pine wood: thickness $250 \mathrm{~mm}(250 \times 310 \times 450 \mathrm{~mm}), \mathrm{MC}=148 \%$; $\mathrm{F}=0.922 \mathrm{GHz}, \mathrm{P}=9 \mathrm{~kW}$, time of $\mathrm{MW}$ heating $-20 \mathrm{sec}, \mathrm{To}=16^{\circ} \mathrm{C}$. Applied energy $180 \mathrm{~kJ}$.

Experiments showed that almost all of the $180 \mathrm{~kJ}$ of applied energy was absorbed in the sample width of $160 \mathrm{~mm}$ in the zones of maximum energy release (for the Comb2 applicator, between $60 \mathrm{~mm}-180 \mathrm{~mm}$ from the beginning of the applicator). In all other zones the energy distribution in the sample width at any depth was very low.

The average MW specific power, applied by the Comb2 applicator, to the wood surface was $9000(\mathrm{~W}): 26(\mathrm{~cm}) \times 16(\mathrm{~cm})=21.6 \mathrm{~W} / \mathrm{cm}^{2}$ and the average MW energy absorbed was $0.43 \mathrm{~kJ} / \mathrm{cm}^{2}$.

Figure 16 displays the temperature distribution as a function of depth in the wood from the Comb2 applicator along the central vertical plane in the zones of maximum energy release $(60-180 \mathrm{~mm}$ from applicator beginning). 


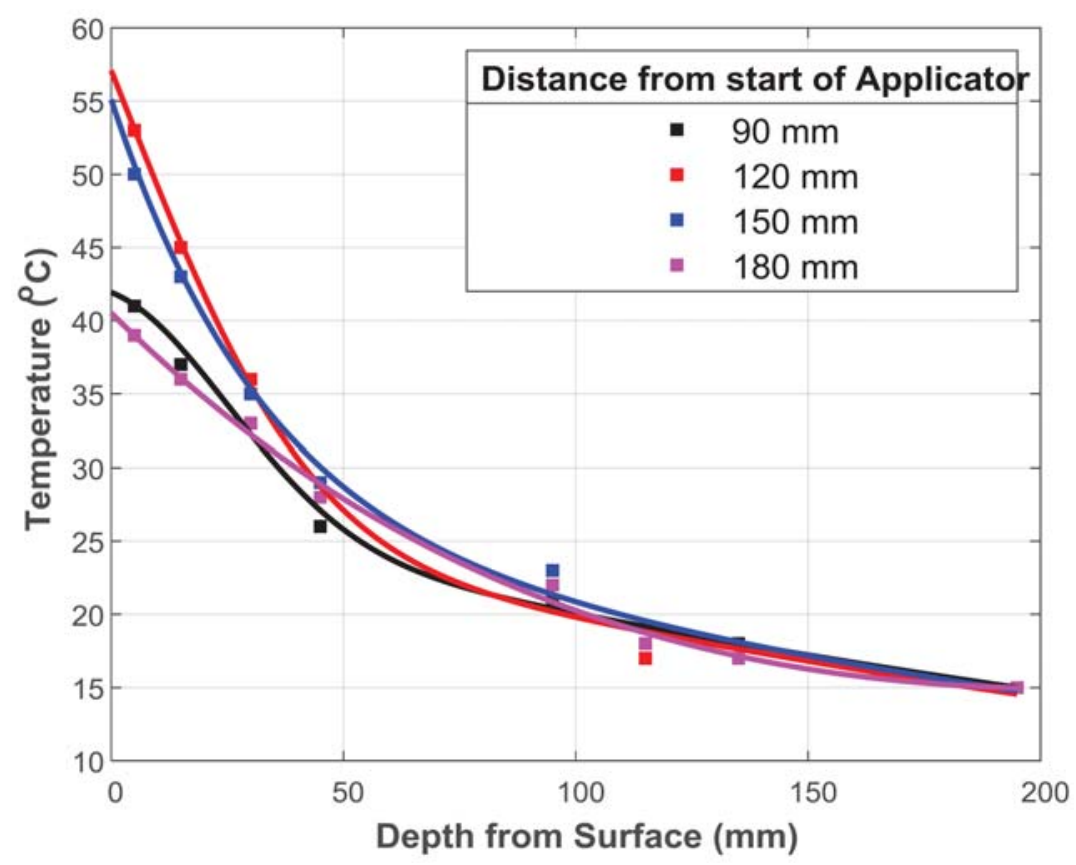

Figure 16. Temperature distribution as a function of depth in the wood from the Comb2 applicator along the central vertical plane. Radiata pine sample: thickness $250 \mathrm{~mm}(250 \times 310 \times 450 \mathrm{~mm}), \mathrm{MC}=148 \% ; \mathrm{F}=0.922 \mathrm{GHz}$, $\mathrm{P}=9 \mathrm{~kW}$, time of MW heating $20 \mathrm{sec}, \mathrm{To}=16^{\circ} \mathrm{C}$. Applied energy $180 \mathrm{~kJ}$.

At the applied energy of $180 \mathrm{~kJ}$, practically all the energy was absorbed within $135 \mathrm{~mm}$ from the timber surface, in the zones of maximum energy release. In all other zones the depth of energy penetration was lower.

In the wood sample with $\mathrm{MC}=148 \%$ the main part of the MW energy was absorbed within about $260 \mathrm{~mm}$ from the beginning of the Comb2 applicator. Across the sample almost all the MW energy was absorbed in the central zone, which was about $160 \mathrm{~mm}$ wide $(+/-80 \mathrm{~mm}$ from central plane of the Comb2 applicator). The average MW specific power applied by the Comb2 applicator to wood surface was $9000(\mathrm{~W}): 16(\mathrm{~cm}) \times 26(\mathrm{~cm})$ $=21.6 \mathrm{~W} / \mathrm{cm}^{2}$ and average MW energy absorbed was $0.43 \mathrm{~kJ} / \mathrm{cm}^{2}$. 


\subsection{Comparison of energy distribution by applicators Comb1 and Comb2}

Comparison of percentage of energy release in timber as a function of depth by applicators Comb1 and Comb2 in the zones of maximum energy release (on distance $30-90 \mathrm{~mm}$ for Comb1 and on distance $90-180 \mathrm{~mm}$ for Comb2 from applicator beginning) is displayed in Figure 17.

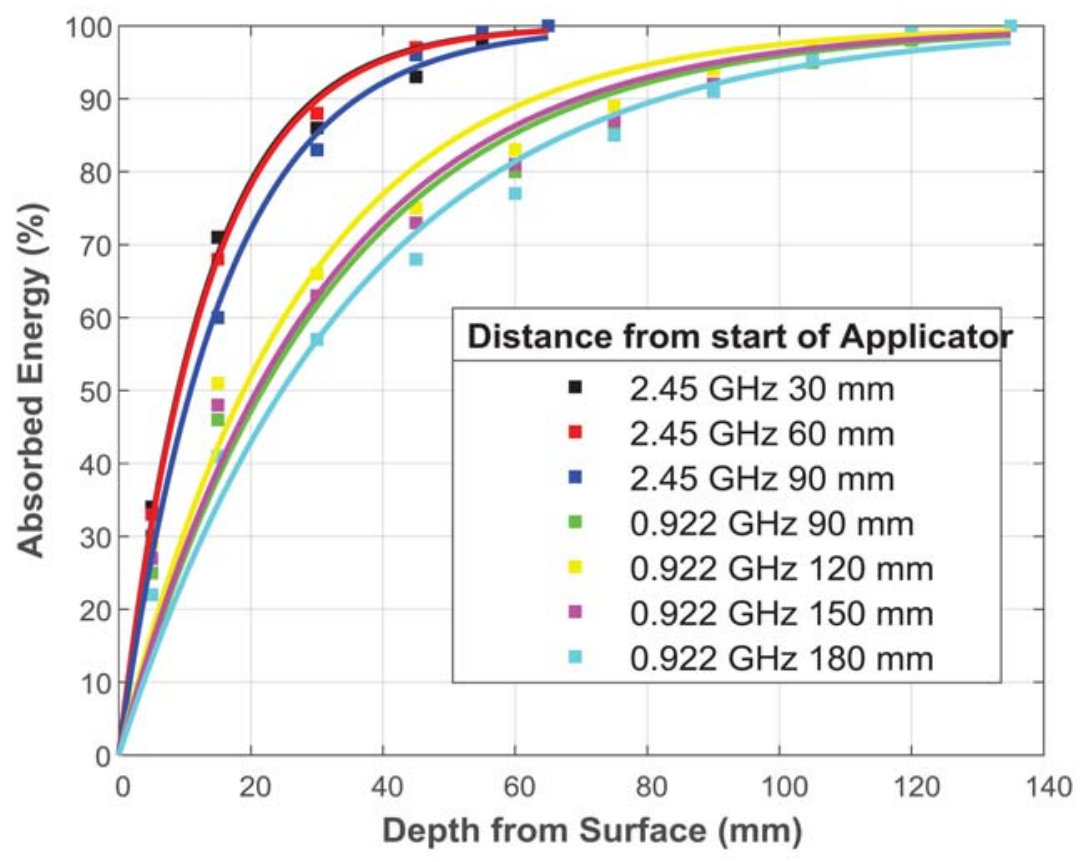

Figure 17. Comparison of percentage of energy release on timber depth applied by applicators Comb1 and Comb2 in zones of maximum energy release (on distance $30-90 \mathrm{~mm}$ for Comb1 and on distance $90-180 \mathrm{~mm}$ for Comb2 from applicator beginning).

Dimensions and energy distribution parameters of applicators Comb1 and Comb2 are displayed in Table 3. 
Table 3. Comparison of sizes and energy distribution parameters of applicators Comb1 and Comb2 in wood with moisture content 148\% and density $1130 \mathrm{~kg} / \mathrm{m}^{3}$

\begin{tabular}{|c|c|c|}
\hline Parameters & Comb1 (2.45GHz) & Comb2 (0.922GHz) \\
\hline Applicator working length, $\mathrm{mm}$ & 356 & 346 \\
\hline Applicator width, mm & 150 & 264 \\
\hline Comb electrode width, $\mathrm{mm}$ & 100 & 150 \\
\hline Average MW specific power applied, W/ $\mathrm{cm}^{2}$ & 18.9 & 21.6 \\
\hline Average MW specific energy applied, $\mathrm{kJ} / \mathrm{cm}^{2}$ & 0.29 & 0.43 \\
\hline MW energy distribution zone width, $\mathrm{mm}$ & 140 & 160 \\
\hline MW energy distribution zone length, $\mathrm{mm}$ & 140 & 260 \\
\hline $\begin{array}{l}\text { Length of zone of high intensity heating along } \\
\text { applicator, } \mathrm{mm}\end{array}$ & $60-90$ & $180-200$ \\
\hline $\begin{array}{l}\text { Depth of full MW energy absorption in zones of } \\
\text { maximum energy release, } \mathrm{mm}\end{array}$ & 50 & 135 \\
\hline $\begin{array}{l}\text { Percentage of energy release on timber depth up } \\
\text { to } 15 \mathrm{~mm} \text { in zone of maximum energy release, } \%\end{array}$ & 68-71 & $41-51$ \\
\hline $\begin{array}{l}\text { Percentage of energy release on timber depth up } \\
\text { to } 30 \mathrm{~mm} \text { in zone of maximum energy release, } \%\end{array}$ & $83-88$ & $57-66$ \\
\hline
\end{tabular}

Experiments with different moisture content materials showed the energy distribution on applicators Comb1 and Comb2 width depends not significantly on moisture content and density in MC range 40 to $140 \%$ and density $600-1100 \mathrm{~kg} / \mathrm{m}^{3}$. Energy distribution along the applicator Comb1 length, at a frequency of $2.45 \mathrm{GHz}$ at low moisture content and wood density can be more than $140 \mathrm{~mm}$ from the start of the applicator; therefore, for practical purposes it is better to have the applicator length not less than 250-280mm. For Comb2 applicator a minimum length $350 \mathrm{~mm}$ is recommended.

Applicator Comb1 provides very high efficiency of energy release at depths up to $30 \mathrm{~mm}-83 \%-88 \%$ in zones with maximum energy application. In other zones energy application efficiency is higher. Comb2 applicator, 
due to longer MW wave length, provides a deeper energy penetration. Efficiency of energy absorption in the zones of maximum energy release at depths up to $30 \mathrm{~mm}$ is about $60 \%$.

There are two main advantages in energy distribution from comb applicators compared with horn applicators. These include: more uniformity of energy distribution along the applicators and significant energy concentration near the applicator's surface (ceramic plates). In MW surface heating systems, the timber (logs, boards) moves along the applicator, which improves the uniformity of energy distribution along the log. Non-uniformity of energy distribution across the log can be compensated by using several applicators, positioned with displacement along the log for overlapping zones with low MW intensity.

Comb applicators can provide required wood top layer treatment (sterilization) with good efficiency and can be recommended for practical use. The Comb1 applicator $(2.45 \mathrm{GHz})$, due to its higher frequency, provides better efficiency for energy release in the top layers of wood, compared to Comb2 $(0.922 \mathrm{GHz})$. But at a frequency of $0.922 \mathrm{GHz}$, the efficiency of electric energy transformation to MW energy is much higher and the price of generators is significantly lower; therefore, the choice of frequency for industrial wood heating use needs to be done from an economic assessment.

\section{Conclusion}

Experiments showed that the Comb1 applicator $(2.45 \mathrm{GHz})$, with alumina ceramic plates, provides the following energy distribution in wood with moisture content of $148 \%$ and density of $1130 \mathrm{~kg} / \mathrm{m}^{3}$ in the tested conditions: along the applicator length $140 \mathrm{~mm}$, on applicator width $-140 \mathrm{~mm}$ and full energy absorption in depths up to $50 \mathrm{~mm}$. The Comb2 $(0.922 \mathrm{GHz})$ applicator, in the tested conditions, provides energy release along the applicator length to $260 \mathrm{~mm}$, on the applicator width $-160 \mathrm{~mm}$ and full energy absorption to depths up to $135 \mathrm{~mm}$. 
The Comb1 applicator provides high efficiency of MW energy release in depths up to $30 \mathrm{~mm}-83-88 \%$ of applied energy in zones with maximum energy application. In other zones energy application efficiency is higher. The Comb2 applicator, due to its longer MW wave length, provides a deeper energy penetration. The efficiency of energy absorption in the zones of maximum energy release to depths up to $30 \mathrm{~mm}$ is about $60 \%$ of applied energy. Energy distribution by comb applicators in the wet wood allows the release of the most significant part of the energy in the surface layers and increases efficiency of energy use compared to other typed of MW radiators. Comb1 and Comb2 applicators are recommended for practical use in wood heating, MW modification and sterilisation processes.

The experimental study of slow wave comb structures, designed for heating surface layers of timber (and other materials: soil, concrete, plaster, bricks and so on), provides effective MW energy release in the wood surface layers by keeping the energy close to the comb surface, spreading energy along applicator and limiting energy penetration into the material. Comb MW applicators are more effective for heating surface layers compared to horn or slot radiators.

\section{References}

[1] P. Blanchet, A. K. Kaboorani and Cecilia Bustos, Understanding the effects of drying methods on wood mechanical properties at ultra and cellular levels, Wood and Fiber Science 48(2) (2016), 117-128.

[2] X. He, X. Xiong, J. Xie, Y. Li, Y. Wei, P. Quan, Q. Mou and X. Li, Effect of microwave pretreatment on permeability and drying properties of wood, BioResources 12(2) (2017), 3850-3863.

[3] M. Khan, G. Brodie and D. Gupta, Effect of microwave (2.45GHz) treatment of soil on yield components of wheat (Triticum aestivum L.), Journal of Microwave Power and Electromagnetic Energy 50(3) (2016), 191-200.

DOI: https://doi.org/10.1080/08327823.2016.1228441 
[4] M. Lemos de Peres, R. Delucis, D. A. Gatto and R. Beltrame, Mechanical behavior of wood species softened by microwave heating prior to bending, European Journal of Wood and Wood Products 74(2) (2016), 143-149.

DOI: https://doi.org/10.1007/s00107-015-0978-x

[5] Yu. N. Pchelnikov, Features of slow waves and potentials for their nontraditional application, Journal of Communications Technology and Electronics 48(4) (2003), 450-462.

[6] Yu. N. Pchelnikov, SWS - based applicators for agriculture application, Unpublished Report for Melbourne University of Company "Pchelnikov Consulting" (2014), pp. 39.

[7] R. A. Silin, Periodic Waveguides, Publisher Fazis, Moscow (2002), [in Russian].

[8] K. Sugiyaento, P. Vinden, G. Torgovnikov and S. Przewloka, Microwave surface modification of Pinus radiata peeler cores: Technical and cost analyses, Forest Products Journal 60(4) (2010), 346-352.

DOI: https://doi.org/10.13073/0015-7473-60.4.346

[9] G. I. Torgovnikov, Dielectric Properties of Wood and Wood Based Materials, Publisher Springer-Verlag, Berlin, 1993.

[10] G. Torgovnikov and P. Vinden, Microwave modification of the peeler cores for preservative treatment, Journal of Materials Science and Engineering with Advanced Technology 9(1) (2014), 51-68.

[11] G. Torgovnikov, P. Vinden and B. Balboni, Microwave conversion of plantation grown Blue gum (Eucalyptus globulues L’Herit) wood to Torgvin and impregnation with metal alloy, Journal of Materials Science and Engineering with Advanced Technology 11(1) (2015), 1-19.

DOI: http://dx.doi.org/10.18642/jmseat_7100121430

[12] G. Torgovnikov and P. Vinden, Microwave wood modification technology and equipment for its commercialization (Conference paper), July 15-29; Cartagena, Spain, $3^{\text {rd }}$ Global Congress on Microwave Energy Applications (3GCMEA), (2016). Proceedings, pp 120-129.

[13] A. Treu and S. Gjolsjo, Spruce impregnation, finally a breakthrough by means of microwave radiation? In: Proc. $4^{\text {th }}$ Meeting of the Nordic Baltic Network in Wood Material Science \& Engineering (WSE), Nov. 13-14, 2008 Riga, Latvia (2008), pp. $42-48$.

[14] US Department of Energy, Industrial Technologies Program, Forest Products, Increasing yield and quality of low-temperature, low-alkali kraft cooks with microwave pretreatment, Project Fact Sheet (2007), 1-2.

[15] P. Vinden, J. Romero and G. Torgovnikov, A method for increasing the permeability of wood, US Patent No 6,596,975 (2003). 
[16] P. Vinden, G. Torgovnikov and J. Hann, Microwave modification of Radiata pine railway sleepers for preservative treatment, European Journal of Wood and Wood Products 69(2) (2011), 271-279.

DOI: https://doi.org/10.1007/s00107-010-0428-8

[17] D. A. Watkins, Topics in Electromagnetic Theory, Publisher Willy \& Sons Inc., N.Y., 1958.

[18] A. A. Yelizarov and Yu N. Pchelnikov, Radio-Wave Elements of Technological Devices and Equipment on Slow-Wave Structures, Publisher Radio and Communications, Moscow (2002), [in Russian].

[19] A. Yelizarov, R. Shaymardanov and Y. Pchelnikov, Methods and apparatus for microwave thermotherapy based on slow-wave systems, (Conference paper), March 14-16, Bochum, Germany. 10th German Microwave Conference, GeMiC 2016. Proceedings (2016). INSPEC Accession Number: 15970025. Publisher IEEE.

DOI: https://doi.org/10.1109/GEMIC.2016.7461606 